\title{
The Logic System is the Way You Do Logic
}

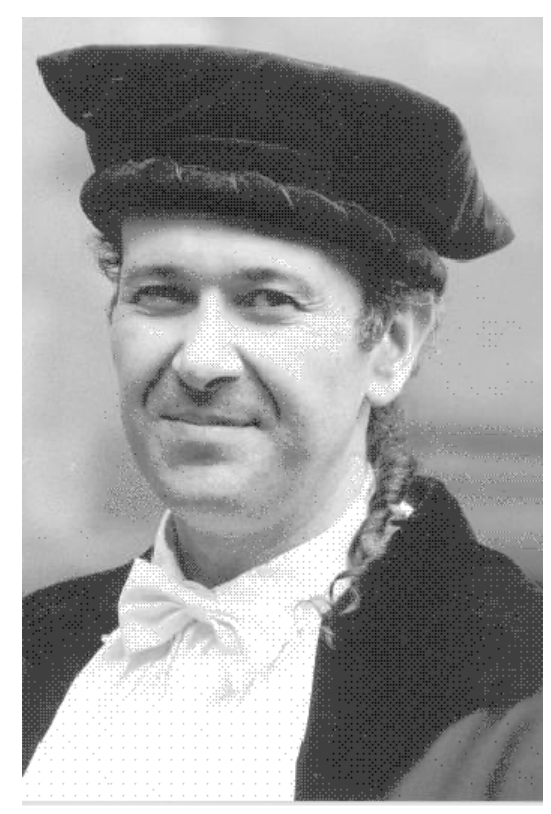

Dov M. Gabbay is Augustus De Morgan Professor (Emeritus) of Logic at the Group of Logic, Language and Computation, Department of Informatics, King's College London. $\mathrm{He}$ is a Special Professor (Emeritus) at the Bar-Ilan University, Israel, and a Visiting Professor at the University of Luxembourg. He has authored or co-authored over five hundred research papers and over thirty research monographs. He is editor of several international journals, and has edited over 50 Handbooks of Logic, including the Handbook of Philosophical Logic, the Handbook of Logic in Computer Science, the Handbook of the History of Logic, and the Handbook of Artificial Intelligence and Logic Programming, among many other reference works on logic. He is Chairman and founder of several international conferences, executive of the European Foundation of Logic Language and Information and President of the International IGPL Logic Group. He is founder, and joint President of the International Federation of Computational Logic. He is also one of the four founders and council member for many years of FoLLI, the Association of Logic, Language and Information, from which he is now retired. He is cofounder with Jane Spurr of College Publications, a not-for-profit academic publisher intended to compete with the major academic publishing houses, offering quick publication at affordable prices, and not requiring copyright assignment from authors.

Andrew Schumann: All the basic forms of modern communication in science have been generated in the early modern period, namely at that time the first scientific communities have been created and the first scientific journals have been established (so, the first scientific community was called Academia secretorum naturae, it was founded in Naples 1560, and the first scientific journal was called Journal des sçavans that started to be published 1665). In the sphere of symbolic logic you are an organizer of many communication platforms for scientists, e.g. you are the editor-in-chief or editor of many scientific journals, book series and most recently you have launched the publishing house, College Publications. Therefore the translation of your family name from Hebrew as the 'head of community' has a symbolic meaning. In logical communities you have organized and promoted high-grade scientific communications. How far traditional formats of scientific communication (submitting to journals, contributing to books, writing books, talking in scientific conferences), as continued since the early modern period, have been till now effective? What are the features of scientific communication in symbolic logic? Does it, perhaps, have the sense to invent absolutely new forms of scientific communication which did not previously exist? For example, an analogue of Wikipedia, i.e. a joint scientific source like Nicolas Bourbaki, but on the Internet?

Dov M. Gabbay: I think that publishing books, journals and so on, and publishing on the Internet allows us to get a lot of information very easily. But what has also happened is that the speed, in which we want to work and publish, has increased a lot, too. And the problem is that we face publishers who want to own scientific sources. I mean that two hundred years ago your publisher was paid for his job to print your paper and to promote it. Nowadays, publishers are handing over information, because they want to possess copyrights, so they don't give copyrights to scientists, i.e. authors. But the web developed very quickly. Sitting at home before writing a paper, you want to 
know, if your paper's possible contents is connected to another paper written by someone else. You go to the web and can find this other paper on a webpage of a journal. Then you have to pay about $\$ 35$ just to take a look at it. And you don't know whether it will be suitable or not for your work. Hence, the situation is frustrating and will become worse.

Andrew Schumann: Maybe some additional questions about the same subject. For example, the speed of spreading some ideas (life-cycle of ideas) in mass-media, in show business is much faster than in scientific circles. Maybe we need some things that give us faster speed in the future in science too, maybe some kind of social networks, especially for logicians.

Dov M. Gabbay: Surely, we need to publish ourselves as widely as possible. But the main reason why it cannot be done at the moment, is because you need to be published in good high impact journals if you want to be promoted at your university. However, we don't have enough good openaccess journals. I have, therefore, worked on a new journal, which I hope will be a good openaccess journal published by College Publications http://www.collegepublications.co.uk/. Notice that this place is a good way to publish scientific monographs with very cheap prices. Recently, there is a movement against publishers because of their attitude to the business. It is a terrible thing - what is happening now. Publishers just want to earn money. They regard the scientific content as a product. They may as well be selling electric toasters. One day, I said to the senior executive of publishing house: 'You wear a suit, you look at spreadsheets and you calculate profits. That is all you care about and as far as you are concerned, you may be selling bagels.'

Andrew Schumann: You anticipate novel trends in symbolic logic, and have even established some. Which new trends in symbolic logic can we expect? What will spark the interest of logicians in the near future?

Dov M. Gabbay: There are things I've already said 20 years ago, but now there are people, who are working in the conventional way, regarding logical systems as theories, i.e. as something static. But I've said that a logical system should not be just what theories are, what you can infer from them, but also contain the way you get to these theories. If you want to construct proof theory by some algorithms, you know that if you change these algorithms even a little bit, you might get a different logical system. In other words, you know that a logical system is a system of algorithms. And to repeat what I said 20 years ago, is that the logical system is a theory consisting of algorithms, but also containing various mechanisms like abduction, comparing, etc., which allowed us to add to this theory. And now I say that the logic system is not just the way it represents data and manipulate it but also contains algorithms of how you get more data and how you change it, evaluate it, label it. In other words it is also dynamics of reasoning, how you move about, how you think, how you execute your actions, part of the logic is also how you use it. So, a logical system is really what is in the head of an agent and the way he is being treated relative to his environment. Logic is human: 'I am a logical system.' So, I think logic should go in that direction. I think logicians will get to this idea sooner or later but this process is very slow, because people are very conservative.

Andrew Schumann: Maybe especially logicians are very conservative.

Dov M. Gabbay: In order to be less conservative, we should work in many areas. For instance, I work in many areas and I see many connections. I see that in order to reconcile what's done here, what's done there and what's done in many other places you need a more general system. Take, for example, belief merging and voting. Voting is studied in social and political sciences and belief merging is studied in logic, but they are very similar processes. Nevertheless, it is what you want to do with in each area that is different. In both cases you have several candidates and you need to reconcile them. So, by looking at these all areas and things, we can guess, where the true facts of logic come from and where logic is going to go. 
Andrew Schumann: For a couple of years now, you have done huge work on formalizing Talmudic logic. You have launched the book series, Studies in Talmudic Logic where the eleven books are already published. What is the general intention of this series? Which books have been published, which are planned? What is it, the logic of the Talmud? What features does it have?

Dov M. Gabbay: The books, which are already published, are written both in Hebrew and English. The Talmud is a set of rules and of arguments and it regulates how we behave. Therefore, it's merely modeling and guiding humans and so it has its own way of looking at what human beings do and what they can do with it. Therefore, if we model the way Talmudic scholars are thinking and the way they are arguing, we can get a new formal logic modelling the principles, which have been important since antiquity. In other words, this logic may cover our experiences of how to follow some temporal reasoning, action reasoning, etc. of the Talmud. In this way, we are forced to create new logics, new ideas and then we export them from the Talmud for modern logic. So, in many cases we have extrapolated new principles that were already in the Talmud, but they are new and not known in modern logic and artificial intelligence like Talmudic temporal logics and Talmudic cognition logics and we make a combination of those concepts and export to modern logic.

For example, the book we are working on now. We are investigating what to do if Rosh Hashanah is on Sabbath, this means that two bodies of laws apply to the same object. So, this is belief revision from the following point of view. We have different predicates $A, B, C$ and then we come with an input, revision, saying $A$ is the same as $B$. And it maybe that $Y$ is true for $A$ and $Y$ is not true for $B$. However, if we say, $A$ equals $B$, we have either $Y$ or not $Y$, i.e. we have to choose between them. And the Talmud doesn't do it like this. The Talmud says: why is $Y$ given for $A$ and why is not- $Y$ given for B? I mean, if we take Rosh Hashanah and Sabbath. On Sabbath we are not allowed to cook. On Rosh Hashanah we are allowed to cook. So, if Rosh Hashanah is on Sabbath are we allowed to cook or not? We don't know. So, we ask: why on Sabbath are we not allowed to cook? We say: cooking is work and Sabbath is the end of creation. So, the reason we don't work on Sabbath is because creation is over and G-d stopped working on creation. And cooking is work. Why on Rosh Hashanah can we or should we cook? It's because it's honouring and welcoming the New Year and we are supposed to be happy, so we are allowed to cook. And now, we understand the reasons for each rule and we can agree on their priorities. But actually, what the Talmud says is different. It says that on Rosh Hashanah, we are also not allowed to cook, but this rule is cancelled, because we are supposed to enjoy ourselves. So, really, if we put them together the determination is clear. We suspend the cancellation. Thus the Talmud uses a calculus of cancellations, a new concept applicable in modern artificial intelligence.

Thus, exporting new ideas and principles in the book series Studies in Talmudic Logic deals with many tasks. And using symbolic logic helps us. I believe that G-d created us as reasoning creatures in His own image. So, if we model Human logic, we get closer to G-d, and better understand His commandments. Let's take a painter. I don't know, which one you like. Perhaps Van Gogh? You see his paintings, so you can admire him by the painting, but not the person as such. However, if you could read the diaries and see the way Van Gogh was thinking we will have a better understanding of him as a person. So, in that similar way you may know how Talmudic logic works and understand another side of G-d. When G-d gave the Ten Commandments He also gave Moses the rules to derive more laws. These rules are closer to G-d's way of thinking.

Andrew Schumann: Why did you decide to be engaged in formalizing the Talmudic logic? What were the reasons: religious, philosophical, scientific? What do you like in Talmudic reasoning? Can we state that formalizing Talmudic reasoning will be useful in symbolic logic? In analytic philosophy? Can it find any application in computer science? Whether the logic hidden in the Talmud is a unified intelligent hyper-large system like Solaris of Stanisław Lem? Is it possible to say that this logic is the logic of the Lord? 
Dov M. Gabbay: I wanted to do the Talmudic logic 50 years ago and I tried. There were many books on Talmudic logic written by Louis Jacobs and many others. But only just now the modern symbolic logic is ready to formalize the Talmudic way of reasoning. Only now after 50 years of developing many logical systems and working in many areas I felt ready that I could deal with it. The problem is that nobody has tried to formalize the Talmudic logic like we are doing in the Studies in Talmudic Logic book series. There are very great thinkers who know the Talmud, but they don't know the whole spread of logic. Suppose that you have been a plumber for 50 years, you would have a garage full of all kinds of things - cords, pipes, screws and screwdrivers, pieces of metals, washers, etc. So, if you see a problem you will immediately know what to do, because you can say: 'I got these little pieces of things from 30 years ago, I can use them here.'

There are very great traditions of Talmudic studies in Yeshibot (Rabbinic schools). And what I can do is to help the students of those schools to learn logical pieces of Talmudic reasoning. There are many people who simply want to study Talmudic logic, many of whom are young. Some students of Yeshibot ask me how many volumes are planned? I said I don't know. Maybe twenty or twenty four, maybe sixty or seventy. I don't know how far it will go. 